\title{
Right Atrial Volume Index to Left Atrial Volume Index Ratio is Associated with Adverse Clinical Outcomes in Cardiogenic Shock
}

\author{
Paras Patel $^{1}$, Patrick Stafford ${ }^{1}$, McCall Walker ${ }^{2}$, Kenneth Bilchick ${ }^{1}$, Olusola Laja ${ }^{1}$, \\ Younghoon Kwon ${ }^{3}$, Sami Ibrahim ${ }^{1}$, Nishaki Mehta ${ }^{4}$, Nishtha Sodhi ${ }^{1}$, Hunter Mwansa ${ }^{5}$, \\ Kanasa Nkanza-Kabaso ${ }^{6}$, Khadijah Breathett ${ }^{7}$, and Sula Mazimba ${ }^{8}$ \\ ${ }^{1}$ University of Virginia Health System \\ ${ }^{2}$ University of Texas Southwestern Medical Center Cardiology Division \\ ${ }^{3}$ University of Washington Department of Medicine \\ ${ }^{4}$ Beaumont Health \\ ${ }^{5}$ St. Vincent Charity Medical Center \\ ${ }^{6}$ University of Cape Town \\ ${ }^{7}$ University of Arizona \\ ${ }^{8}$ University of Virginia
}

July 9,2020

\begin{abstract}
Background: Structural remodeling in chronic systolic heart failure (HF) is associated with neurohormonal and hemodynamic perturbations among HF patients presenting with cardiogenic shock (CS) and HF. Objectives: To test the hypothesis was that atrial remodeling marked by an increased right atrial volume index (RAVI) to left atrial volume index (LAVI) ratio is associated with adverse clinical outcomes in CS. Methods: Patients included were admitted to the intensive care unit with evidence of congestion (pulmonary capillary wedge pressure $>15$ ) and cardiogenic shock (cardiac index $<2.2$, systolic blood pressure $<90$ $\mathrm{mmHg}$, and clinical evidence supporting CS) and had an admission echocardiogram. LAVI and RAVI were measured using the biplane disc summation method by two independent observers. Cox proportional hazards regression analysis was used to assess the association of RAVI-LAVI with the combined outcome of death or left ventricular assist device (LVAD). Results: Among 113 patients (mean age $59 \pm 14.9$ years, 29.2\% female), median RAVI/LAVI was 0.84. During a median follow-up of 12 months, 43 patients died, and 65 patients had the combined outcomes of death or LVAD.Patients with RAVI/LAVI ratio above the median had a greater incidence of death or LVAD (Log-rank $\mathrm{p}=<0.001$ ), and increasing RAVI/LAVI was significantly associated with the outcomes of death or LVAD (HR 1.71 95\% CI 1.11-2.64, chi square 5.91, p=0.010) even after adjustment for patient characteristics and hemodynamic variables. Conclusion: RAVI/LAVI is an easily assessed novel echocardiographic parameter with strong associations with the survival or the need for mechanical circulatory support in patients with CS.
\end{abstract}

\section{Introduction}

Cardiogenic shock (CS) is one of the most dreaded complications of chronic systolic heart failure (HF), and is marked by a state of end-organ hypoperfusion due to reduction in cardiac output. CS is defined by the hemodynamic parameters of: decreased cardiac index, hypotension, and elevated left ventricular filling pressures [1]. Despite advancements in therapeutics and mechanical support devices, patients with CS still experience excessively high mortality rates in the contemporary era.

Risk stratification of CS still remains a challenge for clinicians. HF is associated with structural remodeling due to both neurohormonal and hemodynamic perturbations [2]. It is well established that the integrity 
of the right ventricle (RV) is a key determinant of prognosis in HF with reduced left ventricular ejection fraction (HFrEF) [3]. Further, right atrial (RA) volume and size is an important indicator of RV remodeling. Prior studies have shown that an increased RA volume is an independent predictor of adverse outcomes in patients with HF $[4,5]$. It has also been shown that the ratio of right atrial volume index (RAVI) to left atrial volume index (LAVI), RAVI/LAVI, is associated with adverse outcomes in pulmonary hypertension [6].Therefore, we hypothesized that the RAVI/LAVI, as measured by two dimensional doppler echocardiography, is independently associated with death and LVAD implantation in patients with HF presenting with CS.

\section{Methods}

\section{Study Design and Patient Cohort}

We retrospectively evaluated consecutive patients admitted to the coronary care unit at a single academic tertiary care center from October 2013 to March 2016. Patients were included if they had a prior diagnosis of HFrEF (left ventricular ejection fraction $<40 \%$ ), and CS. CS was defined as pulmonary capillary wedge pressure $(\mathrm{PCWP})>15 \mathrm{mmHg}$, cardiac index $<2.2$, and sustained systolic blood pressure $<90 \mathrm{mmHg}$ or the need for vasopressor use. Patients were included in the study if they met the above hemodynamic inclusion criteria and had adequate echocardiographic images for the calculation of RAVI/LAVI. Baseline characteristics and hospital data were obtained from the Clinical Data Repository and chart review. Patients with a diagnosis of CS in the post-operative setting, after myocardial infarction, or with concomitant sepsis were excluded. The cohort was then stratified by the median RAVI/LAVI, as well as RAVI/LAVI quartiles in order to analyze the relationship between RAVI/LAVI with clinical outcomes. The primary outcome was death or implantation of LVAD. The study was approved by the institutional review board of the University of Virginia.

\section{Echocardiography}

All patients underwent a clinically indicated 2D echocardiogram during their admission according to published guidelines [7]. Standard echocardiographic images in the parasternal, apical, and subcostal views in the left lateral decubitus position were obtained by experienced echocardiography technologists. RAVI was measured using the single plane disc summation method in the four-chamber view, while LAVI was measured using the biplane disc summation method in the four and two-chamber views [7] (Figure 1). All studies were performed using the Philips IE33 or Epiq 7CV (Philips Medical Systems, Andover, MA) or GE Vivid E9 Ultrasound (GE, Milwaukee, WI) systems and were analyzed and processed using Enterprise Imaging (Agfa Healthcare N.V., Mortsel, Belgium). Echocardiographic analyses were performed by two independent investigators who were blinded to clinical outcomes.

\section{Invasive Hemodynamics}

Hemodynamic variables, including right atrial pressure (RAP), pulmonary arterial (PA) pressure/mean, and PCWP were obtained from the right heart catheterization or PA catheter data at the time of diagnosis of CS. The hemodynamic tracings were obtained and recorded at end-expiration [8]. Cardiac index was measure using the indirect Fick method (with an assumed $\mathrm{O} 2$ consumption of $125 \mathrm{~mL} / \mathrm{min} / \mathrm{m}^{2}$ BSA).

\section{Statistical Analysis}

Data were collected and analyzed using SPSS@ (version 24) and R (version 3.5.1). Continuous variables were expressed as mean \pm standard deviation, and categorical variables were expressed as frequency and percentages. Differences among continuous variables for two groups (patients with RAVI/LAVI above or below the median) was assessed using a two-sample t-test, and analysis of variance was used to assess differences in continuous variables among more than two groups (patients in different quartiles of RAVI/LAVI). Chi-squared tests were used to assess differences among categorical variables. A p-value $<0.05$ was considered statistically significant.

Kaplan Meier curves were used to assess the differences in time to survival with stratification based on either the median value of RAVI/LAVI or quartiles of RAVI/LAVI. The proportional hazards assumption was 
confirmed by visual inspection of the survival curves, and the log rank test was utilized to test whether there was a significant difference between groups with the proportional hazards assumption met. The BreslowWilcoxon method was considered as an alternative if the proportional hazards assumption had not been confirmed.

A multivariable Cox proportional hazards model was used to examine the association of RAVI/LAVI with death or implantation of LVAD. An alpha value of less than 0.05 was used for statistical significance.

Intraobserver variability among measurements was assessed in 113 patients using the intraclass correlation coefficient. Bland-Altman plots were constructed for both RAVI and LAVI.

\section{Results}

\section{Baseline characteristics}

There were 113 patients admitted to the coronary care unit with complete hemodynamic and echocardiographic data available for inclusion in the study. The median age was $59 \pm 14.9$ years, and $29.2 \%$ of the patients were female. Other baseline characteristics are shown in Table 1. Forty-three patients died during a median follow-up of 1 year, and 65 patients experienced the combined outcomes of death or LVAD.

\section{Intraobserver Variability for RAVI/LAVI}

The median values of RAVI, LAVI, and RAVI/LAVI were 22.46, 28.36, and 0.83, respectively. Among 113 patients, intraobserver variability was excellent for both RAVI (ICC 0.965) and LAVI (ICC 0.956) as shown in Figures 3.

\section{Differences among Patients with RAVI/LAVI Stratified by the Median}

As shown in Table 1, type 2 diabetes was less prevalent in patients with RAVI/LAVI above the median (p $=0.048)$. There was no statistical difference regarding the etiology of HF, home medications, or the use of mechanical support during hospitalization. Patients with a RAVI/LAVI above the median were noted to have a higher admission B-type natriuretic peptide (BNP) compared with patients with RAVI/LAVI below the median $(\mathrm{p}=0.038)$. Hemodynamic and echocardiographic profiles stratified by median RAVI/LAVI are shown in Table 3. There was no statistical difference with respect to CVP, PA mean, PCWP, TPG, CI, MAP, LVEF, or RAP/PCWP between the two groups. RAVI was significantly higher in the RAVI/LAVI greater than median group $(\mathrm{p}=<0.001)$.

\section{Differences among Patients with RAVI/LAVI Stratified by Quartiles}

When stratified into quartiles, RAVI was noted to increase in size each quartile $(\mathrm{p}=<0.001)$, while LAVI decreased in size per quartile $(\mathrm{p}=0.026)$. With RAVI/LAVI stratified into quartiles (Table 2$)$, only the admission BNP was noted to be significantly different with higher values in Q3 and Q4 (2454 \pm 1919 and $3954 \pm 1455$, respectively) $(\mathrm{p}=0.020)$. There was no significant difference in the hemodynamic variables between groups (Table 4).

\section{Association of RAVI/LAVI with Survival}

Patients with RAVI/LAVI ratio above the median had a greater incidence of death or LVAD (Log-rank $\mathrm{p}=<0.001$ ) (Figure 2). When divided into quartiles, patients in quartile 3 and quartile 4 had a significantly higher incidence of death and LVAD transplantation $(\mathrm{p}=<0.001)$ (Figure 3$)$. Fewer patients in the RAVI/LAVI strata above the median were discharged alive from the hospital. In a multivariable Cox proportional hazards regression model, increasing RAVI/LAVI was associated with the outcomes of death or LVAD transplantation (HR 1.71, 95\% CI 1.11-2.64, chi square 5.91, $\mathrm{p}=0.010$ ). There was no significant association with the outcome of death and LVAD transplantation with RAVI or LAVI when analyzed as independently stratified by the median ( $\mathrm{p}=0.230$ and 0.250 respectively).

\section{Discussion}


In patients with CS, a higher RAVI/LAVI was significantly associated with adverse clinical outcomes. When stratified into quartiles, there was nearly a 2 -fold and 3-fold increase in death and LVAD implantation in the third and fourth quartiles respectively when comparted to the first and second quartiles.

CS is a grave complication of HF with very high mortality [9]. Determinants of outcomes among patients with CS are poorly understood because of paucity of studies as well as a heterogeneity in patient characteristics [10]. Even less understood are the determinants of outcomes among patients with CS in the setting of "acute on chronic" decompensated HF [11]. Chronic HF is a progressive disease that is associated with structural remodeling due to neurohormonal and hemodynamic changes. Among these patients, the integrity of the right ventricular function determines clinical outcomes [12,13,14]. A compromised RV is associated with worse outcomes $[15,16]$.

Unfortunately, the routine evaluation of the RV function on transthoracic echocardiogram had been neglected until recently. It has been shown that RAVI/LAVI, a novel index that reflects important inter-atrial interactions and RV dysfunction is associated with poor outcomes in patients with pulmonary hypertension [6]. In present study, we have also shown that RAVI/LAVI is also associated with adverse outcomes in CS. Prior studies have established that RA dilatation is a key indicator of the integrity of the RV functional status [17].

The RA is a thin walled chamber with a limited capacitance for the increased pressure load. Sustained pressure load on the RA leads to chamber dilatation rather than hypertrophy based on the law of Laplace. A dilated RA leads to leftward bowing of the interatrial septum thereby constraining the left atrium (LA).

In advanced stages of HFrEF with adverse remodeling, concurrent RV dysfunction occurs in up to $65 \%$ of patients with HFrEF [14,18]. As noted in this study, CS patients with higher RAVI/LAVI had significantly higher levels of BNP reflecting a structural milieu of adverse remodeling due to persistently elevated filling pressures. Thus, RAVI/LAVI is an index that constitutively integrates multiple hemodynamic variables between the left and right sides of the heart, and more specifically the pressure-volume interactions with inter-atrial structural remodeling. These results not only highlight the important interactions between left and right heart systems but also underscore the importance of identifying RA/LA structural remodeling in patients with HFrEF presenting with CS. CS is a lethal condition which requires timely initiation of advanced HF therapies in order to mitigate the downward trajectory of end organ function that ultimately leads to death. As we demonstrate, there were no differences in baseline patient characteristics between the RAVI/LAVI groups suggesting that patient co-morbidities, alone, are insufficient in prognostication in CS patients. Thus the utility of a non-invasive parameter such as RAVI/LAVI is a clinically readily available tool that can help risk stratify CS patients and guide management in a time sensitive manner. Indeed the identification of patients likely to suffer imminent adverse outcomes in HFrEF with CS is critical to the timely adjudication of the need for advanced HF therapies.

\section{Limitations}

Our sample size was limited by the number of patients with complete hemodynamic data and with good quality echocardiographic images for the measurement of RA/LA volumes. Although 2D Echo is widely available and considered a useful tool for the measurement of the atrial dimensions and function, it is however limited by the absence of an orthogonal plane and reliance on geometric assumptions of atrial chambers [19]. For these reasons, 3D Echo is considered to be superior to 2D Echo [20]. Acquisition of quality 2D echo is limited in the setting of ventilation, obesity, pulmonary edema, and the limited ability to position patients with cardiogenic shock. Although the echo images were not obtained simultaneously with the hemodynamic measurements, changes in atrial size happen over time due to atrial remodeling in the setting of volume or pressure overload.

\section{Conclusion}

In HFrEF patients with CS, RAVI/LAVI is an easily assessed novel echocardiographic parameter. Increasing RAVI/LAVI is associated with adverse clinical outcomes including death and need for durable mechanical 
support. These findings suggest need for further investigation into the use of RAVI/LAVI as a prognostic indicator in CS.

\section{Author Contributions:}

Each of the co-authors contributed in a substantial and meaningful way to the creation of this manuscript. Paras Patel and Patrick Stafford participated in data collection, interpretation, and analysis, drafting and revision of the manuscript, and approval of the finalized version. McCall Walker, Sami Ibrahim, and Olusola Laja participated in data collection and interpretation. Kenneth Bilchick participated in data interpretation and analysis. Younghoon Kwon, Nishaki Mehta, Nishtha Sodhi, Khadijah Breathett, Hunter Mwansa and Kanasa Kabaso critically reviewed the manuscript. Sula Mazimba participated in conception and design, revision of content, and final approval.

Key Words: Cardiogenic Shock, Chronic Systolic Heart Failure, Right Atrial Volume Index, Outcomes

\section{References:}

1. Reynolds HR, Hochman JS. Cardiogenic shock. Circulation 2008; 117:686-697.

2. Hartupee J, Mann D. Neurohormonal activation in heart failure with reduced ejection fraction. Nat Rev Cardiol 14, 30-38 (2017).

3. Carluccio E, Biagioli P, Alumni G, et al. Prognostic value of right ventricular dysfunction in heart failure with reduced ejection fraction. Circ Cardiovasc Imaging. 2018;11:e006894.

4. Sallach JA, Tang WH, Borowski AG, et al. Right atrial volume index in chronic systolic heart failure and prognosis. J Am Coll Cardiol 2009; 2:527-534.

5. Darahim K. Usefulness of right atrial volume index in predicting outcome in chronic systolic heart failure. J Saudi Heart Assoc. 2014;26(2):73-79.

6. Mysore, MM, Bilchick, KC, Ababio, P, et al. Right atrial to left atrial volume index ratio is associated with increased mortality in patients with pulmonary hypertension. Echocardiography. 2018; 35: 17291735 .

7. Lang RM, Badano LP, Mor-Avi, V, et al: Recommendation for cardiac chamber quantification by echocardiography in adults: An update from the American Society of Echocardiography and the European Association of Cardiovascular Imaging. J. Am. Soc. Echocardiogr 2015; 28(1):1-39.

8. Deano RC, Glassner-Kolmin C, Rubenfire M, et al: Referral of patients with pulmonary hypertension diagnoses to tertiary pulmonary hypertension centers: The Multicenter rePHerral Study. JAMA Intern Med. 2013:173(10):887-893

9. Rudiger A, Harjola VP, Muller A, et al. Acute heart failure: Clinical presentation, one-year mortality and prognostic factors. The European Journal of Heart Failure 2005; 7:662-670.

10. Mosterd A, Hoes AW. Clinical epidemiology of heart failure Heart: 2007; 93:1137-1146.

11. Jones TL, Nakamura K, McCabe JM. Cardiogenic shock: evolving definitions and future directions in management. Open Heart 2019;6:e000960.

12. Ghio S, Guazzi M, Scardovi AB, et al. Different correlates but similar prognostic implications for right ventricular dysfunction in heart failure patients with reduced or preserved ejection fraction. Eur J Heart Fail. 2017; 19:873-879.

13. Mohammed SF, Hussain I, AbouEzzeddine O, et al. Right ventricular function in heart failure with preserved ejection fraction: a community-based study. Circulation. 2014; 130:2310-2320

14. Iglesias-Garriz I, Olalla-Gómez C, Garrote C, et al. Contribution of right ventricular dysfunction to heart failure mortality: a meta-analysis. Rev Cardiovasc Med. 2012; 13 :e62

15. Frea S, Pidello S, Bovolo V, et al. Prognostic incremental role of right ventricular function in acute decompensation of advanced chronic heart failure. Eur J Heart Fail. 2016; 18:564-572.

16. Polak JF, Holman BL, Wynne J,Colucci WS. Right ventricular ejection fraction: an indicator of increased mortality in patients with congestive heart failure associated with coronary artery disease. J Am Coll Cardiol1983;2:217-24.

17. Cioffi G, de Simone G, Mureddu G, Tarantini L. Right atrial size and function in patients with pulmonary hypertension associated with disorders of respiratory system or hypoxemia. Eur J Echocardiography 
2007:8:322-331.

18. Lewis JF, Webber JD, Sutton LL, Chesoni S, Curry CL. Discordance in degree of right and left ventricular dilation in patients with dilated cardiomyopathy: recognition and clinical implications. J Am Coll Cardiol. 1993;21:649-654.

19. Marsan NA, Tops LF, Holman ER, et al. Comparison of left atrial volumes and function by realtime three-dimensional echocardiography in patients having cathete ablation for atrial fibrillation with persistence of sinus rhythm versus recurrent atrial fibrillation three months later. Am J Cardiol. 2008; 102: $847-853$.

20. Lang RM, Badano LP, Tsang W, et al. EAE/ASE recommendations for image acquisition and display using three-dimensional echocardiography. Eur Heart J Cardiovasc Imaging. 2012; 13( 1): 1- 46.

Table I. Baseline Demographic and Clinical Characteristics Stratified by Median RAVI/LAVI.

\begin{tabular}{llll}
\hline Characteristic & Below Median $(\mathrm{n}=56)$ & Above Median $(\mathrm{n}=56)$ & $\mathrm{p}$-value \\
Age & $61.5 \pm 13.7$ & $58.78 \pm 16.2$ & 0.282 \\
Female Sex & $14(24.6)$ & $19(33.9)$ & 0.375 \\
Coronary Artery Disease & $41(71.9)$ & $31(55.7)$ & 0.102 \\
Type 2 Diabetes Mellitus & $34(59.6)$ & $22(39.3)$ & 0.048 \\
Chronic Kidney Disease & $24(42.1)$ & $27(48.2)$ & 0.643 \\
Chronic Obstructive Pulmonary Disease & $16(28.1)$ & $10(17.9)$ & 0.286 \\
Hypertension & $36(63.2)$ & $32(57.1)$ & 0.645 \\
Hyperlipidemia & $33(57.9)$ & $36(64.3)$ & 0.614 \\
Tobacco Abuse & $37(64.9)$ & $33(58.9)$ & 0.645 \\
Beta Blocker & $34(59.6)$ & $38(67.9)$ & 0.477 \\
ACEi* / ARB+ & $26(45.6)$ & $27(48.2)$ & 0.930 \\
Aldosterone Antagonist & $15(26.3)$ & $17(30.4)$ & 0.789 \\
Diuretic & $38(66.7)$ & $43(76.8)$ & 0.325 \\
Home Inotrope & $4(7.0)$ & $7(12.5)$ & 0.506 \\
Mechanical Cardiac Support & $21(38)$ & $26(46)$ & 0.348 \\
Admission Lactic Acid & $2.9 \pm 2.5$ & $3.1 \pm 2.0$ & 0.819 \\
Admission Brain Natriuretic Peptide & $1664.8 \pm 1163.5$ & $2592.6 \pm 2019.3$ & 0.01 \\
Admission Creatinine & $1.8 \pm 1.1$ & $1.9 \pm 1.1$ & 0.478 \\
\hline
\end{tabular}

Values are presented as mean \pm standard deviation or $\mathrm{n}(\%) .{ }^{*} \mathrm{ACEi}$ is angiotensin converting enzyme inhibitor, +ARB is angiotensin receptor blocker.

Table II. Baseline Demographic and Characteristics by Quartiles of RAVI/LAVI.

\begin{tabular}{|c|c|c|c|c|c|}
\hline Characteristic & $\begin{array}{l}\text { RAVI/LAVI Q1 } \\
(<0.620)(\mathrm{n}=29)\end{array}$ & $\begin{array}{l}\text { RAVI/LAVI Q2 } \\
(0.620-0.840) \\
(\mathrm{n}=28)\end{array}$ & $\begin{array}{l}\text { RAVI/LAVI Q3 } \\
(0.840-1.120) \\
(\mathrm{n}=28)\end{array}$ & $\begin{array}{l}\text { RAVI/LAVI Q4 } \\
([?] 1.120)(\mathrm{n}=28)\end{array}$ & p-value \\
\hline Age & $59.8 \pm 15.2$ & $63.3 \pm 12.0$ & $56.1 \pm 17.6$ & $60.8 \pm 14.5$ & 0.755 \\
\hline Female Sex & $7(24.1)$ & $7(25.0)$ & $12(42.9)$ & $7(25.0)$ & 0.339 \\
\hline $\begin{array}{l}\text { Coronary } \\
\text { Artery Disease }\end{array}$ & $21(72.4)$ & $20(71.4)$ & $15(53.6)$ & $16(57.1)$ & 0.329 \\
\hline $\begin{array}{l}\text { Type } 2 \\
\text { Diabetes } \\
\text { Mellitus }\end{array}$ & $18(62.1)$ & $16(57.1)$ & $12(42.9)$ & $10(35.7)$ & 0.164 \\
\hline $\begin{array}{l}\text { Chronic } \\
\text { Kidney } \\
\text { Disease }\end{array}$ & $13(44.8)$ & $11(39.3)$ & $14(50.0)$ & $13(46.4)$ & 0.879 \\
\hline
\end{tabular}




\begin{tabular}{|c|c|c|c|c|c|}
\hline \multirow{2}{*}{\multicolumn{6}{|c|}{$\begin{array}{l}\text { Obstructive } \\
\text { Pulmonary } \\
\text { Disease }\end{array}$}} \\
\hline & & & & & \\
\hline Hypertension & $19(65.5)$ & $17(60.7)$ & $14(50.0)$ & $18(64.3)$ & 0.625 \\
\hline Hyperlipidemia & $16(55.2)$ & $17(60.7)$ & $17(60.7)$ & $19(67.9)$ & 0.809 \\
\hline Tobacco & $19(65.5)$ & $18(64.3)$ & $15(53.6)$ & $18(64.3)$ & 0.772 \\
\hline \multicolumn{6}{|l|}{ Abuse } \\
\hline Beta Blocker & $18(62.1)$ & $16(57.1)$ & $20(71.4)$ & $18(64.3)$ & 0.733 \\
\hline $\begin{array}{l}\mathrm{ACEi}^{*} / \\
\mathrm{ARB}+\end{array}$ & $14(48.3)$ & $12(42.9)$ & $12(42.9)$ & $15(53.6)$ & 0.930 \\
\hline $\begin{array}{l}\text { Aldosterone } \\
\text { Antagonist }\end{array}$ & $8(27.6)$ & $7(25.0)$ & $10(35.7)$ & $7(25.0)$ & 0.785 \\
\hline Diuretic & $21(72.4)$ & $17(60.7)$ & $21(75.0)$ & $22(78.6)$ & 0.480 \\
\hline Home Inotrope & $3(10.3)$ & $1(3.6)$ & $3(10.7)$ & $4(14.3)$ & 0591 \\
\hline $\begin{array}{l}\text { Admission } \\
\text { Lactic Acid }\end{array}$ & $2.4 \pm 2.1$ & $3.5 \pm 2.7$ & $2.6 \pm 1.6$ & $3.4 \pm 2.3$ & 0.314 \\
\hline $\begin{array}{l}\text { Admission } \\
\text { Brain }\end{array}$ & $\begin{array}{l}1743.2 \pm \\
1343.9\end{array}$ & $\begin{array}{l}1608.9 \pm \\
1014.2\end{array}$ & $\begin{array}{l}2454.2 \pm \\
1919.0\end{array}$ & $\begin{array}{l}3954.2 \pm \\
1455.2\end{array}$ & 0.020 \\
\hline $\begin{array}{l}\text { Natriuretic } \\
\text { Peptide }\end{array}$ & & & & & \\
\hline $\begin{array}{l}\text { Admission } \\
\text { Creatinine }\end{array}$ & $1.6 \pm 0.9$ & $1.9 \pm 1.2$ & $1.8 \pm 1.0$ & $2.1 \pm 1.1$ & 0.198 \\
\hline
\end{tabular}

Values are presented as mean \pm standard deviation or $\mathrm{n}(\%) .{ }^{*} \mathrm{ACEi}$ is angiotensin converting enzyme inhibitor, +ARB is angiotensin receptor blocker.

Table III. Hemodynamic and Clinical Parameters Stratified by Median RAVI/LAVI.

\begin{tabular}{llll}
\hline & Below Median $(\mathrm{n}=56)$ & Above Median $(\mathrm{n}=56)$ & $\mathrm{p}$-value \\
Right Atrial Volume Index (RAVI) & $18.8 \pm 9.5$ & $32.6 \pm 18.6$ & $<0.001$ \\
Left Atrial Volume Index (LAVI) & $32.7 \pm 15.4$ & $27.3 \pm 14.4$ & 0.056 \\
Pulmonary Artery Systolic Pressure (PASP) & $45.5 \pm 16.2$ & $44.2 \pm 13.1$ & 0.768 \\
Pulmonary Artery Diastolic Pressure (PADP) & $25.1 \pm 10.8$ & $23.5 \pm 6.9$ & 0.557 \\
Mean Pulmonary Artery Pressure (MPAP) & $36.1 \pm 11.8$ & $37.2 \pm 11$ & 0.657 \\
Pulmonary Capillary Wedge Pressure (PCWP) & $21.6 \pm 6.8$ & $20.5 \pm 8.9$ & 0.606 \\
Transpulmonary Gradient (TPG) & $8.8 \pm 10.4$ & $10.4 \pm 7$ & 0.324 \\
Cardiac Index (CI) & $1.7 \pm 0.4$ & $1.7 \pm 0.3$ & 0.863 \\
Mean Arterial Pressure (MAP) & $74.4 \pm 13.8$ & $71.4 \pm 10.3$ & 0.238 \\
Left Ventricular Ejection Fraction (LVEF) & $15.4 \pm 9$ & $18 \pm 14$ & 0.265 \\
RAP/PCWP & $0.5 \pm 0.2$ & $0.6 \pm 0.3$ & 0.410 \\
Death/LVAD & $23(40.4)$ & $42(75)$ & $<0.001$ \\
Discharge Alive & $30(52.6)$ & $12(21.4)$ & 0.001 \\
Discharge Hospice & $2(3.5)$ & $3(5.4)$ & 0.984 \\
\hline
\end{tabular}

Values are presented as mean \pm standard deviation. $*$ RAP/PAWP, right atrial pressure / pulmonary capillary wedge pressure.

Table IV. Hemodynamic and Clinical Parameters by quartiles of RAVI/LAVI. 


\begin{tabular}{|c|c|c|c|c|c|}
\hline Characteristic & $\begin{array}{l}\text { RAVI/LAVI Q1 } \\
(<0.620)(\mathrm{n}=29)\end{array}$ & $\begin{array}{l}\text { RAVI/LAVI Q2 } \\
(0.620-0.840) \\
(\mathrm{n}=28)\end{array}$ & $\begin{array}{l}\text { RAVI/LAVI Q3 } \\
(0.840-1.120) \\
(\mathrm{n}=28)\end{array}$ & $\begin{array}{l}\text { RAVI/LAVI Q4 } \\
([?] 1.120)(\mathrm{n}=28)\end{array}$ & p-value \\
\hline $\begin{array}{l}\text { Right Atrial } \\
\text { Volume Index } \\
\text { (RAVI) }\end{array}$ & $15.9 \pm 8.3$ & $21.9 \pm 9.7$ & $27.3 \pm 12.6$ & $37.9 \pm 22.1$ & $<0.001$ \\
\hline $\begin{array}{l}\text { Left Atrial } \\
\text { Volume Index } \\
\text { (LAVI) }\end{array}$ & $35.1 \pm 16.8$ & $30.2 \pm 13.6$ & $28 \pm 13$ & $26.5 \pm 15.8$ & 0.026 \\
\hline $\begin{array}{l}\text { Pulmonary } \\
\text { Artery Systolic } \\
\text { Pressure } \\
\text { (PASP) }\end{array}$ & $51.5 \pm 18.5$ & $36.9 \pm 5.6$ & $48.3 \pm 14.6$ & $41.5 \pm 11.5$ & 0.198 \\
\hline $\begin{array}{l}\text { Pulmonary } \\
\text { Artery } \\
\text { Diastolic } \\
\text { Pressure } \\
\text { (PADP) }\end{array}$ & $28.5 \pm 12.6$ & $20.2 \pm 4.4$ & $24.6 \pm 8.2$ & $22.7 \pm 5.9$ & 0.191 \\
\hline $\begin{array}{l}\text { Mean } \\
\text { Pulmonary } \\
\text { Artery } \\
\text { Pressure } \\
\text { (MPAP) }\end{array}$ & $37.9 \pm 11$ & $34.3 \pm 12.5$ & $37.1 \pm 11.9$ & $37.3 \pm 10.5$ & 0.943 \\
\hline $\begin{array}{l}\text { Pulmonary } \\
\text { Capillary } \\
\text { Wedge } \\
\text { Pressure } \\
\text { (PCWP) }\end{array}$ & $23.2 \pm 7.5$ & $19.6 \pm 5.4$ & $21.5 \pm 10.7$ & $19.7 \pm 7.9$ & 0.678 \\
\hline $\begin{array}{l}\text { Transpulmonary } \\
\text { Gradient } \\
\text { (TPG) }\end{array}$ & $7.4 \pm 11.6$ & $10.2 \pm 9.1$ & $10.7 \pm 6$ & $10.2 \pm 8$ & 0.228 \\
\hline $\begin{array}{l}\text { Cardiac Index } \\
\text { (CI) }\end{array}$ & $1.8 \pm 0.3$ & $1.6 \pm 0.4$ & $1.6 \pm 0.3$ & $1.7 \pm 0.3$ & 0.994 \\
\hline $\begin{array}{l}\text { Mean Arterial } \\
\text { Pressure } \\
\text { (MAP) }\end{array}$ & $76.5 \pm 15$ & $72.1 \pm 12.3$ & $70.9 \pm 8.9$ & $71.9 \pm 11.6$ & 0.170 \\
\hline $\begin{array}{l}\text { Left } \\
\text { Ventricular } \\
\text { Ejection } \\
\text { Fraction } \\
\text { (LVEF) }\end{array}$ & $14.5 \pm 9.6$ & $16.5 \pm 8.3$ & $19.8 \pm 16.4$ & $16.2 \pm 11.1$ & 0.402 \\
\hline $\mathrm{RAP} / \mathrm{PCWP}^{*}$ & $0.5 \pm 0.2$ & $0.6 \pm 0.2$ & $0.6 \pm 0.3$ & $0.6 \pm 0.3$ & 0.215 \\
\hline $\begin{array}{l}\text { Death/LVAD } \\
\text { Discharge }\end{array}$ & $\begin{array}{l}12(41.4) \\
16(55.2)\end{array}$ & $\begin{array}{l}11(39.3) \\
14(50)\end{array}$ & $\begin{array}{l}20(71.4) \\
7(25)\end{array}$ & $\begin{array}{l}22(78.6) \\
5(17.9)\end{array}$ & $\begin{array}{l}0.003 \\
0.007\end{array}$ \\
\hline $\begin{array}{l}\text { Alive } \\
\text { Discharge to } \\
\text { Hospice }\end{array}$ & $0(0)$ & $2(7.1)$ & $1(3.6)$ & $2(7.1)$ & 0.499 \\
\hline
\end{tabular}

Values are presented as mean \pm standard deviation. $*$ RAP/PAWP, right atrial pressure / pulmonary capillary wedge pressure. 
Figure 1: Apical 4 chamber view measuring right atrial volume and left atrial volume (left) and apical 2 chamber view measuring left atrial volume (right). The atrial chambers were traced at end diastole and volumes were calculated using the biplane disc summation method.

Legend: The figure represents measurement of the right and left atrium in the apical 4 chamber and 2 chamber views. The purpose of this figure is to demonstrate the method of measuring the chambers as well as depict the RAVI/LAVI ratio.

Figure 2: Kaplan-Meyer curve of RAVI/LAVI of patients above and below the median with time measured in days.

Legend: The purpose of this figure is to demonstrate the difference in freedom from death or LVAD when stratified by median RAVI/LAVI. Kaplan Meier curves were used to assess the variance in survival probability for those above and below the median. As demonstrated by the figure, there is a significant difference in outcomes when stratified by the median RAVI/LAVI.

Figure 3: Kaplan-Meyer curve of RAVI/LAVI when compared by quartiles with time measured in days.

Legend: The purpose of this figure is to demonstrate the difference in freedom from death or LVAD when stratified by quartiles of RAVI/LAVI. Kaplan Meier curves were used to assess the variance in survival probability for those above and below the median. The figure demonstrates that outcomes are worse as the RAVI/LAVI ratio increases by quartile.

Figure 4: Bland-Altman plot for intra-observer variability with LAVI (left) and RAVI (right).

Legend: The figure represents the intraclass correlation coefficient of RAVI and LAVI. The purpose of this figure is to demonstrate the consistency of the measurements made by the two independent observers.

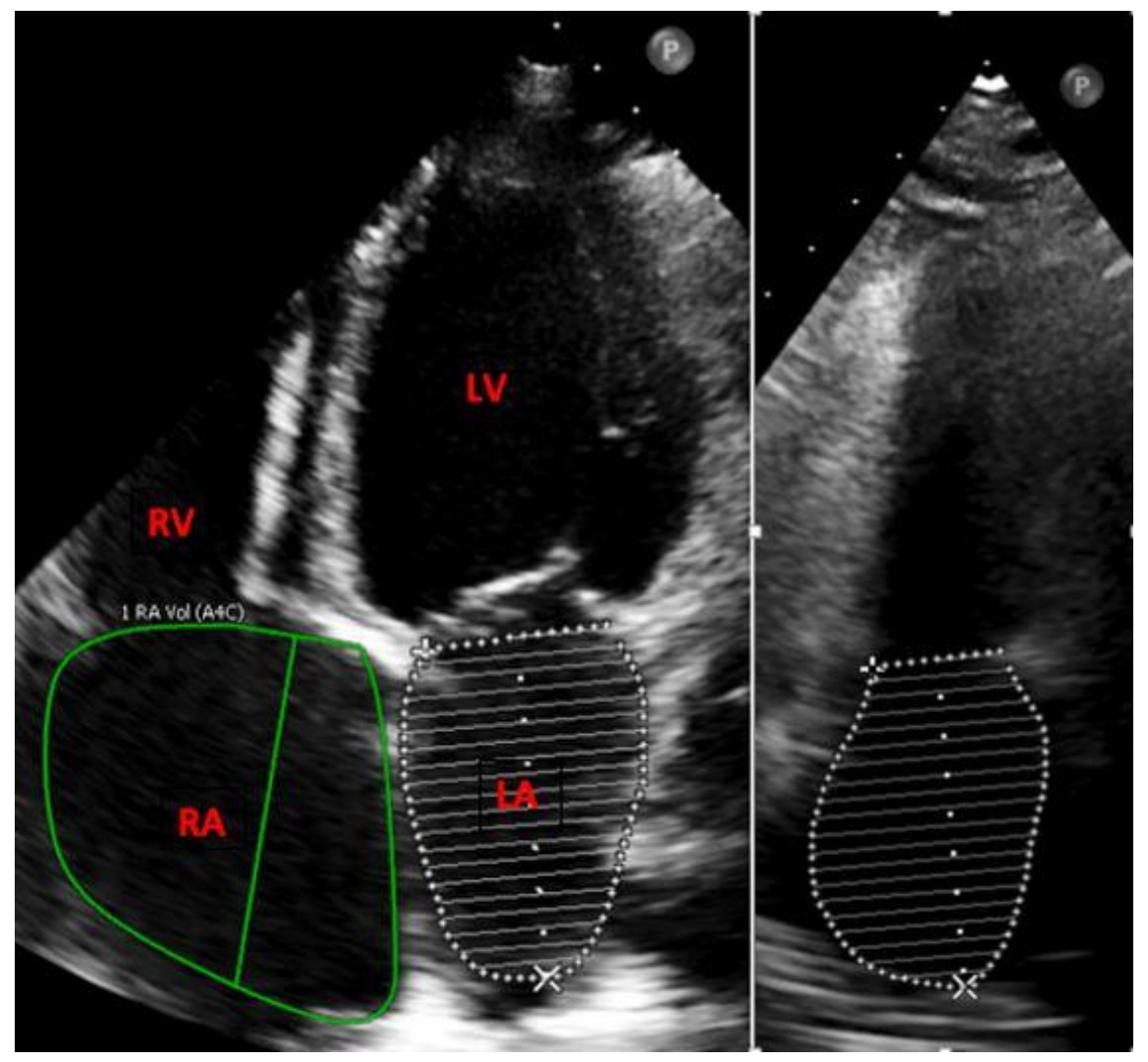



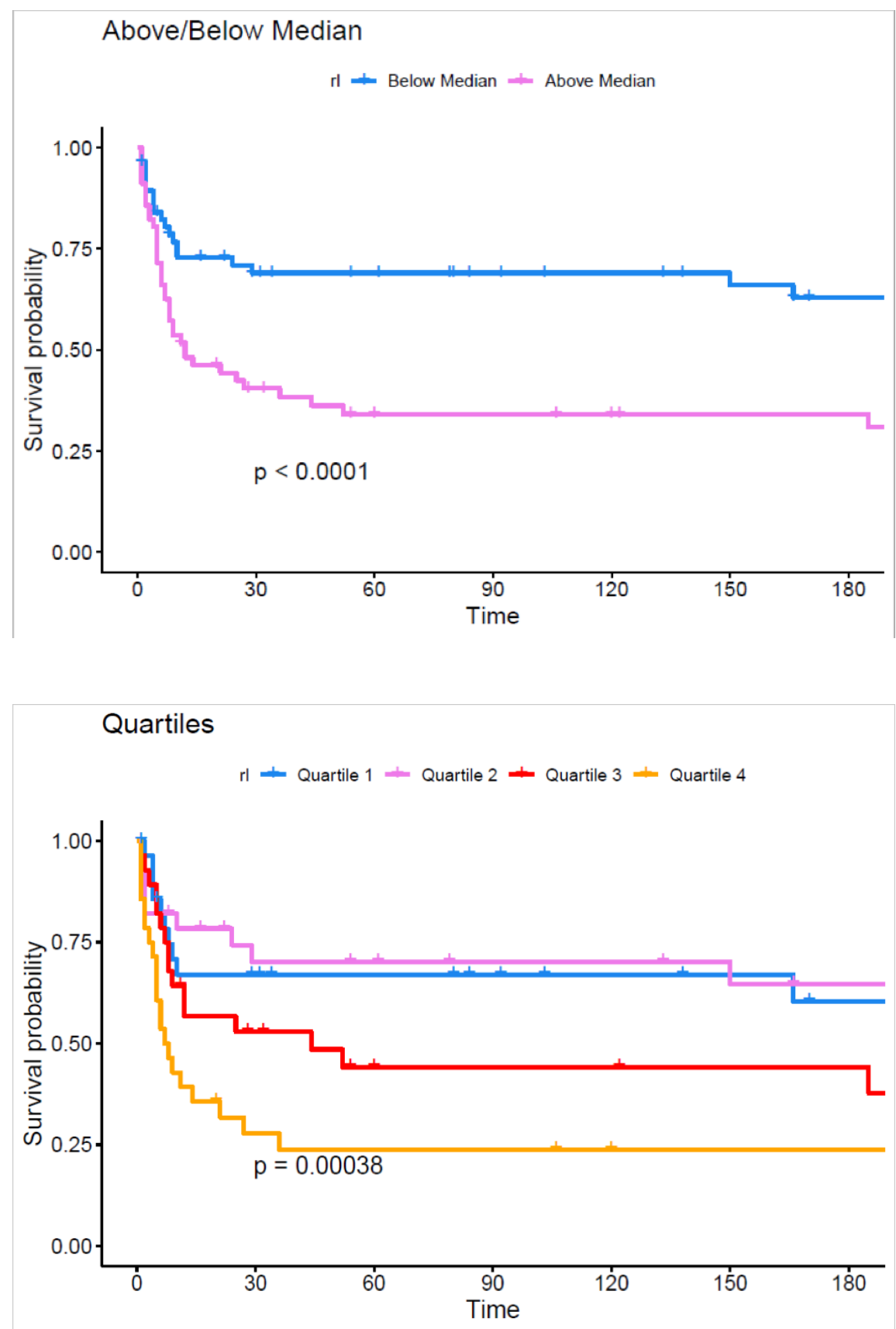


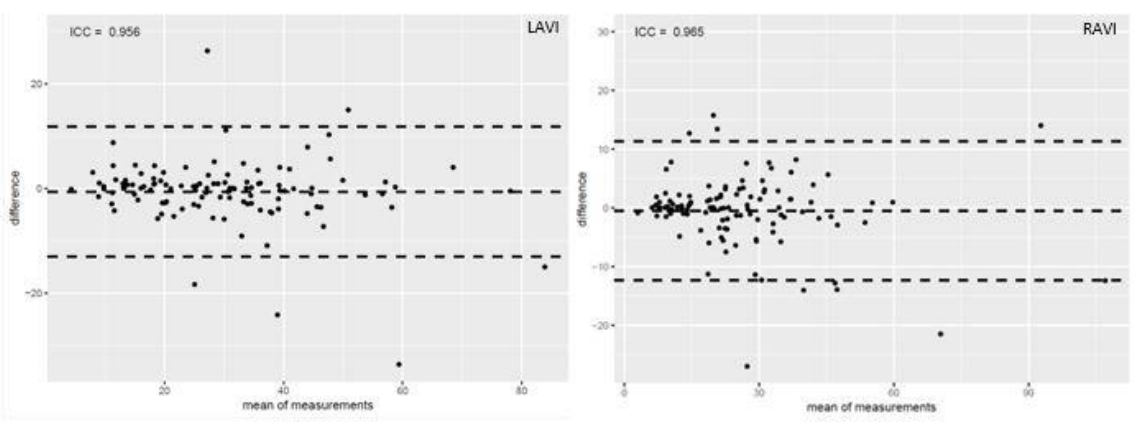

